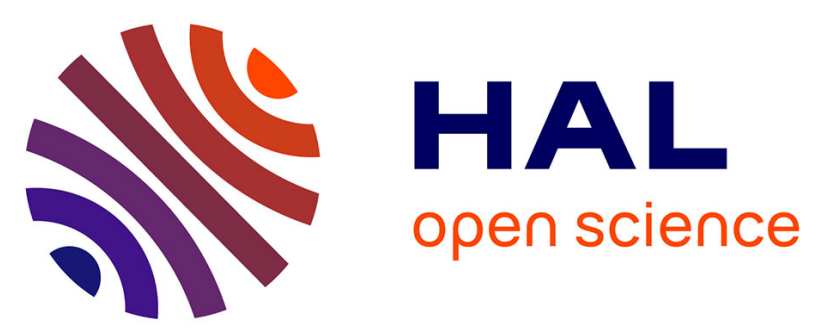

\title{
DEVELOPMENT AND STUDY OF THE UNK SUPERCONDUCTING DIPOLE MODELS
}

N. Andreyev, V. Balbekov, E. Bulatov, Yu. Dmitrevskiy, V. Dolzhenkov, K. Gertsev, V. Gridasov, K. Myznikov, V. Sytnik, N. Tarakanov, et al.

\section{- To cite this version:}

N. Andreyev, V. Balbekov, E. Bulatov, Yu. Dmitrevskiy, V. Dolzhenkov, et al.. DEVELOPMENT AND STUDY OF THE UNK SUPERCONDUCTING DIPOLE MODELS. Journal de Physique Colloques, 1984, 45 (C1), pp.C1-249-C1-253. 10.1051/jphyscol:1984150 . jpa-00223706

\section{HAL Id: jpa-00223706 https://hal.science/jpa-00223706}

Submitted on 1 Jan 1984

HAL is a multi-disciplinary open access archive for the deposit and dissemination of scientific research documents, whether they are published or not. The documents may come from teaching and research institutions in France or abroad, or from public or private research centers.
L'archive ouverte pluridisciplinaire HAL, est destinée au dépôt et à la diffusion de documents scientifiques de niveau recherche, publiés ou non, émanant des établissements d'enseignement et de recherche français ou étrangers, des laboratoires publics ou privés. 


\title{
DEVELOPMENT AND STUDY OF THE UNK SUPERCONDUCTING DIPOLE MODELS
}

\author{
N.I. Andreyev, V.I. Balbekov, E.A. Bulatov, Yu. P. Dmitrevskiy, \\ V.I. Dolzhenkov, K.F. Gertsev, V.I. Gridasov, K.P. Myznikov, V.V. Sytnik, \\ N.M. Tarakanov, L.M. Vasiliev, V.A. Vasiliev and V.V. Yelistratov \\ Institute for High Energy Physics, Serpukhov, Moscow Region, U.S.S.R.
}

Résumé - L'expérience acquise lors de l'étude de modẽles courts a permis de réaliser et d'essayer deux dipôles longs de $6 \mathrm{~m}$. Les essais se sont déroulés dans le cryostat à immersion sans fer. La première transition a rêvélé un courant de 1 'ordre de $6 \mathrm{kA}$ ce qui correspond au champ dans un aimant de $5 \mathrm{~T}$ avec le fer. Le courant maximum est de $6,5 \mathrm{kA}$. Les pertes totales pour le courant de $6 \mathrm{kA}$ et à la vitesse de 1 'injection de $100 \mathrm{~A} / \mathrm{s}$ sont de $750 \mathrm{j} / \mathrm{c}$. Les valeurs absolues des composantes harmoniques du champ dans la partie centrale du dipôle correspondent aux valeurs thêoriques et sont proches des valeurs admissibles. Elles dépendent peu du niveau du champ ce qui prouve une bonne stabilité mécanique et une faible déformation de la bobine à l'échelle 1 .

\begin{abstract}
Two full-scale dipole models, $6 \mathrm{~m}$ long each, have been manufactured in the scope of the programme on development of superconducting dipoles for the UNK. Results of their tests in a bath cryostat are reported. A number of short models have been manufactured and tested with view to improve the integral characteristics of the magnetic field. The results of magnetic measurements of the central and edge field are presented. Also reported are the results of study of training and dynamic characteristics of dipoles.
\end{abstract}

IHFP continues work on simulation of superconducting dipole magnets for the 3 TeV UNK /1/. Proceeding from the construction of the previous series of short models $/ 2 /$, designed to obtain a $5 \mathrm{~T}$ bore field induction there have been manufactured a few models of a new series from a superconducting cable with improved current density and a diameter of filaments of $10 \mu \mathrm{m}$. These models made it possible to obtain the uNK working field in the bore without training and to have a reserve in the critical current necessary in case of increased heat releases in the winding due to irradiation. Based on the experience in working out short models /3/, two 6-m ful1-scale models have been manufactured. Tests of the first long models showed reproducibility of the results obtained for short models.

\section{FULL-SCALE MODELS}

IHEP dipoles as those of FNAL / 4 / have a two-shell winding with some distinct design features allowing an increase in the bore field up to $5 \mathrm{~T}$. Due to a high rield intensity of a proton beam accelerated in the UNK they should have a reserve in the critical current which could provide a stable operation of magnets with possible particle losses.

The cross-sectional view of the dipoles is given in fig. 1 and their basic characteristics are presented in Table 1 .

For these models, the cable has been manufactured from $0.85 \mathrm{~mm}$ in diameter strands. Each strand contains $2970 \mathrm{Nb}-\mathrm{Ti}$ filaments, $10 \mu \mathrm{m}$ in diameter, embedded into a copper natrix with a packing factor of $42 \%$. The cable was transposed from 23 strands, 12 of which were coated by $\mathrm{Sn}-5 \mathrm{wt} \% \mathrm{Ag}$ with a $75 \mathrm{~mm}$ transposition pitch. The keystoned cable was $10.55 \mathrm{~mm}$ in height, the outer width was $1.68 \mathrm{~mm}$ and the inner one was $1.34 \mathrm{~mm}$ (without insulation). The cable was insulated by two layers of a $20 \mu \mathrm{m} 1 \mathrm{avsan}$ tape and $100 \mu \mathrm{m}$ thick epoxy-impregnated fiber-glass tape with a $4 \mathrm{~mm}$ gap between the adjacent turns. 
Table 1

THE BASIC CHARACTERISTICS OF A DIPOLE

\begin{tabular}{llll}
\hline Inner radius of the 1st shell & $\mathrm{mm}$ & 45.16 \\
Angle of the 1st she11 $\alpha_{2}$ & $\mathrm{deg}$ & 72.425 \\
Angle of the 2nd shell $\alpha_{2}$ & $\mathrm{deg}$ & 36.532 \\
Number of turns in the 1st shell & & $2 \times 39$ \\
Number of turns in the 2nd shell & & $2 \times 24$ \\
Total length of shells & $\mathrm{mm}$ & 5925 \\
Ratio B/I with iron & $\mathrm{T} / \mathrm{kA}$ & 0.880 \\
Ratio B/I without iron & $\mathrm{T} / \mathrm{kA}$ & 0.753 \\
\hline
\end{tabular}

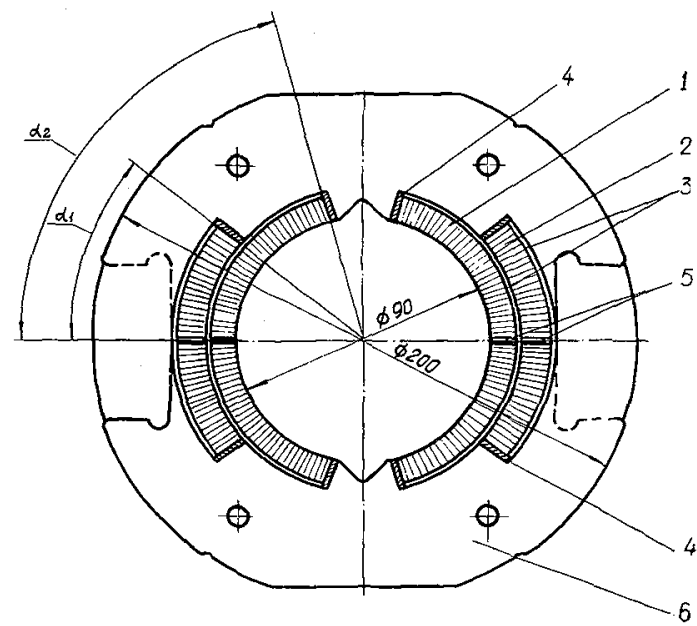

Fig. 1 - Magnet cross-section: inner coil shell (1), outer shell (2), helium flow channels (3), spacers (4), insulating spacers (5), bandage (6).

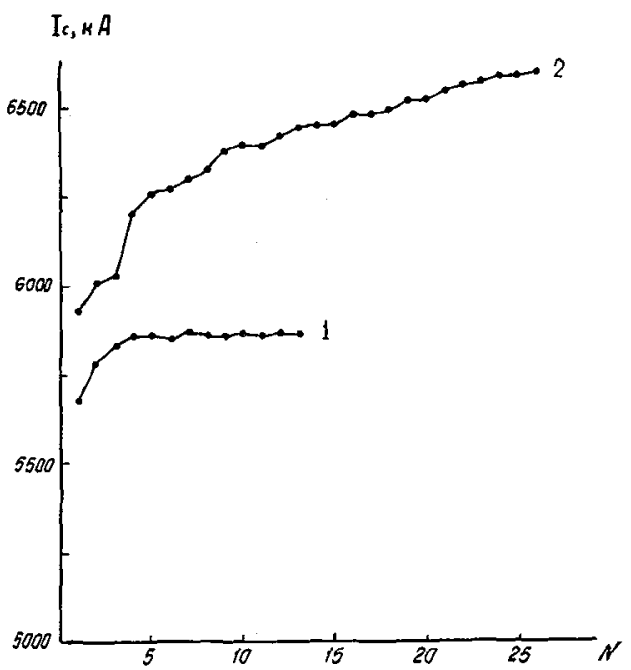

Fig. 2 - The training curves for full-scale models: I - model DD-1, 2 - model DD-2.
The models have been tested without an iron yoke in a bath cryostat with pool-boiling helium. The training curves for the two models are shown. in fig. 2. For the first model, the maximum field was attained after the $3 d$ quench. It exceeded by only $3 \%$ the field attained at the 1st quench. The maximum value of the attained current coincides with that of a short sample to an accuracy of $2.5 \%$. The magnet has repeatedly been tested within every two months after warming up to the ambient temperature. Each time, the current attained its maximum value already at the lst quench and its value was reproduced to an accuracy of $10 \mathrm{~A}$. A second magnet model has been manufactured from a superconducting material with an improved current density. During just the 1st quench its current was $6 \mathrm{kA}$. At higher currents, there was a long-term training obserm ved. After 26 quenches the attainable current was $6.6 \mathrm{kA}$, corresponding a bore field of $5 \mathrm{~T}$ without an iron shield.

A detailed study of harmonics of central field nonlinearity has been made for both magnets. Inaccuracy of measuring the relative values of field harmonics did not exceed $5 \cdot 10^{-5}$ for nonlinearities lower than the 5 th order and $10^{-4}$ for higher-order nonlinearities /5/. Figs. 3 and 4 show even and odd nonlinearities*), respectively, at a distance of $35 \mathrm{~mm}$ from the centre versus the magnet current. The analysis shows that within the $70 \mathrm{~mm}$ bore diameter the field nonlinearities are close to those calculated for both full-scale magnets and keep. their values unchanged within tolerances in a working field range from $0.67 \mathrm{~T}$ to $5 \mathrm{~T}$.

The dynamic losses measured in the trapezoidal cycles current changes for the $100 \mathrm{~A} / \mathrm{sec}$ ramp rate and $6 \mathrm{kA}$ amplitude (the real cycle of the UNK) were $750 \mathrm{~J}, 550 \mathrm{~J}$ being hysteresis losses.

The full-scale dipole models are taken as the basis for further development. One of the models is assembled now in a force-circulating cryostat with a magnet shield (fig. 5) and is ready to be tested at a forcecirculating cryogenic test facility.

*) The coefficient $C_{n}$ corresponding to the nonlinearity of the order of $n-1$. 


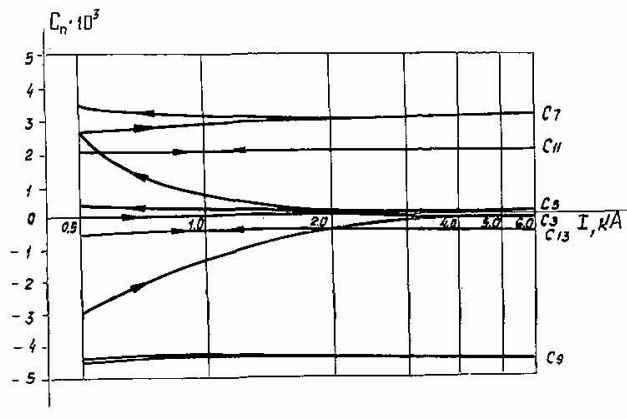

Fig. 3 - Normal even nonlinearities versus magnet current.

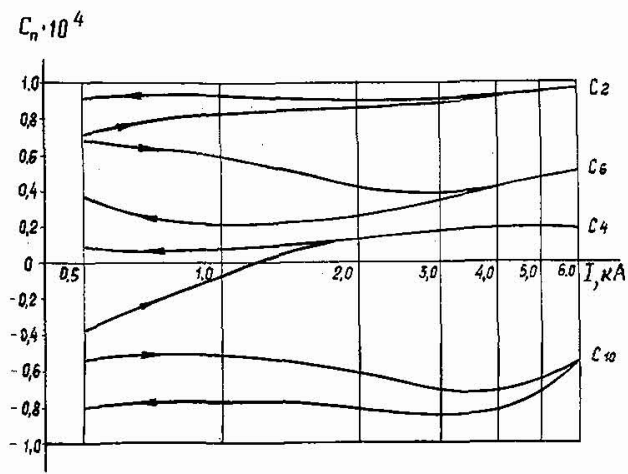

Fig. 4 - Normal odd nonlinearities verșus magnet current.

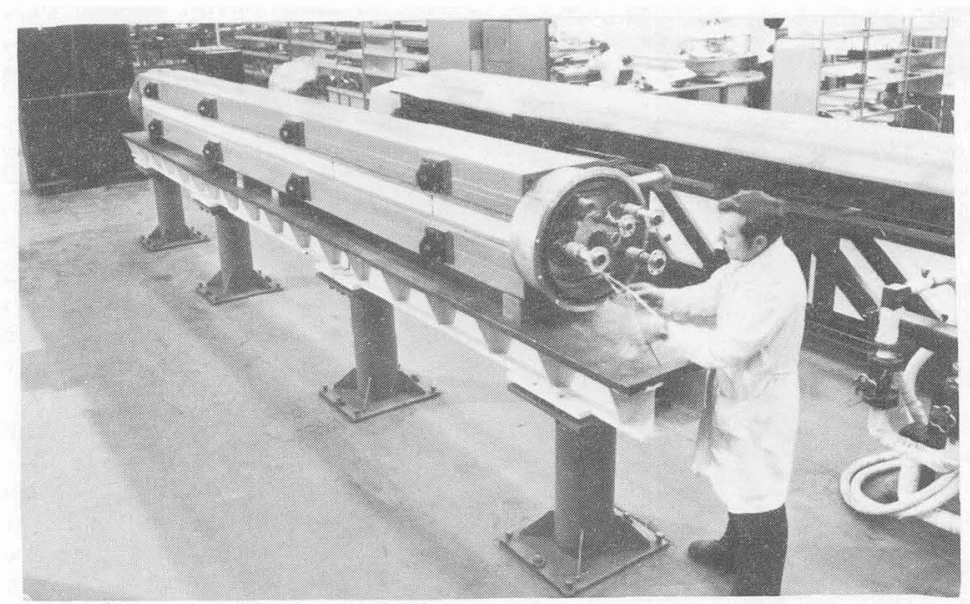

Fig. 5 - A full-scale dipole model in a force-circulating cryostat.

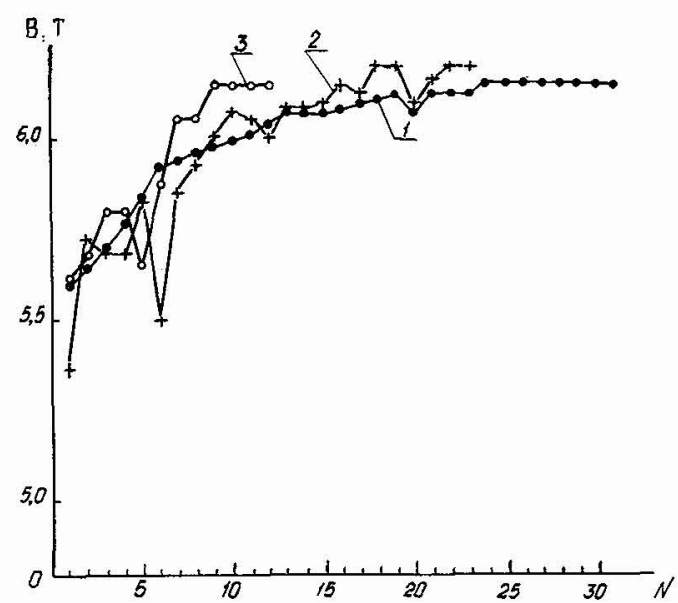

Fig. 6 - The training curves for new short dipole models.

\section{STUDY OF SHORT MODELS}

Study of short models is going on. A few models with an improved current density of the cable have been manufactured. Being tested in a bath cryostat at a temperature of $4.25 \mathrm{~K}$ these models with an iron shield provide bore field of about $5.5 \mathrm{~T}$ after the 1st quench. Fig. 6 shows the training curves for three magnets of this series. As seen, after some training the maximum fiela attained was $6.2 \mathrm{~T}$. With a temperature of the helium bath down first to $3.9 \mathrm{~K}$ and then to $3.65 \mathrm{~K}$ the maximum field attained was $6.55 \mathrm{~T}$ and $6.7 \mathrm{~T}$, respectively, after a short-term training at each level ( $3-4$ quenches). The harmonic analysis has been done for each field level. Besides, with the help of resistor-type strain gauges the dependence of radial bandage movement due to pon- 


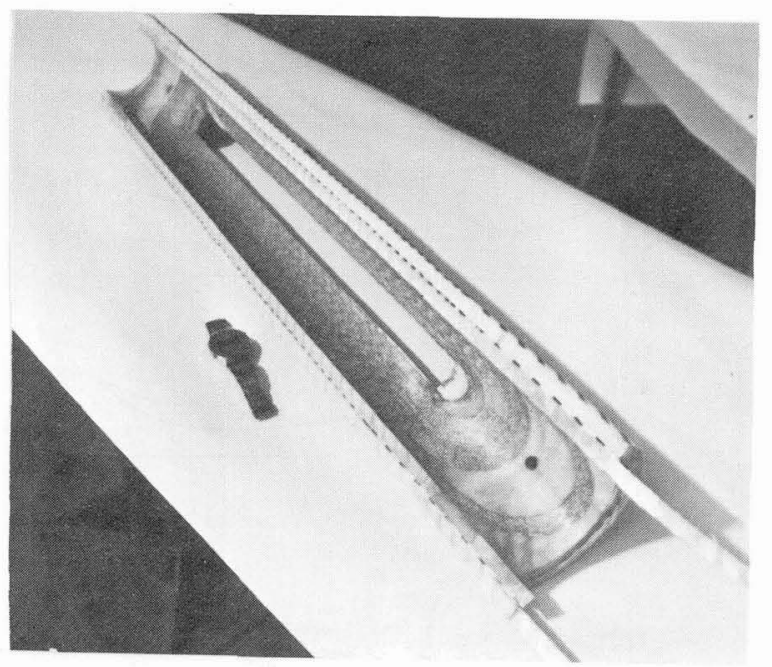

Fig. 7 - A half-coil of a short model; the layout of turns on the edges is seen.

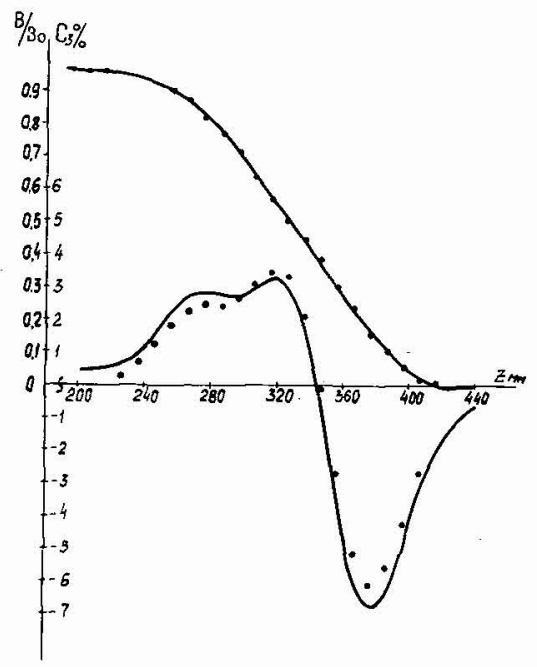

Fig. 8-The dipole and sextupole components of the edge magnetic field. The dashed line is for the calculation, the points are for the experimental values. deromotive forces has been measured. As shown by these measurements, the relative values of harmonics deviate from those tolerable by $1 \cdot 10^{-4}$ at a field exceeding $6 \mathrm{~T}$, which is accompanied by a bandage deformation by above $100 \mu \mathrm{m}$. So, the developed construction has a good mechanical stability at the UNK working field and also a necessary reserve in the critical current.

UNK ful1-scale dipoles to be manufactured are supposed to be rectilinear. In this case stringent requirements are imposed on the edge field quality. The relative values of harmonics $\mathrm{C}_{3}$ and $\mathrm{C}_{5}$ should satisfy the conditions

$\left|\int_{\Delta s} \mathrm{C}_{3} \mathrm{ds}\right|<3,5 \cdot 10^{-3} \mathrm{~m}$ and $\left|\int_{\Delta s} \mathrm{C}_{5} \mathrm{ds}\right|<4 \cdot 10^{-4} \mathrm{~m}$,

where $\Delta s$ is the end lendth. To meet these requirements, the turns at the edges were laid in such a way that the integral values of harmonics $\mathrm{C}_{3}$ and $\mathrm{C}_{5}$ in the edge field be close to zero /6/. Fig.7 shows the picture of these windings. The end part of the winding of the inner shell has a $11.2 \mathrm{~mm}$ wide fiberglass spacer after the 4 th turn and a $47.2 \mathrm{~mm}$ wide one after the 30-th turn. The outer layer has not such spacers. Fig. 8 shows the design and measured dependences of dipole and sextupole components of the edge field on the longitudinal coordinate measured from the middle of the dipole. The calculated and experimental data are in a satisfactory agreement. The way of laying out turns at the winding edges made it also possible to improve the integral characteristics of the dipole field. The contributions from the edge field into lower-order nonlinearities are within tolerances for the case of a full-scale dipole. 


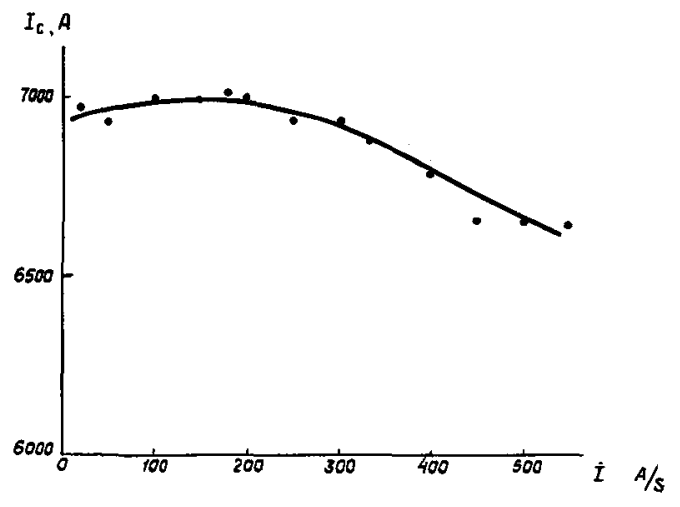

Fig. 9 - The critical current of a short model versus ramp rate.
Dynamic characteristics of dipoles have been measured. Fig. 9 shows a dependence of the critical current on the ramp rate typical for the dipoles of this series. As seen in the the whole range of rates up to $250 \mathrm{~A} / \mathrm{sec}$ the quench current remains unchanged.

Presently the work on dipole study continues.As a next step, a study will be made of their operational peculiarities in force-circulating cooling mode.

\section{REFERENCES}

/1/ BALBEKOV V.I., DMITREVSKIY Yu.P., DUNAITSEV A.F. et al, "The IHEP Accelexating and Storage Complex (UNK). Status Report", Report at XII International Conference on High Energy Accelerators, FNAL, 1983.

/2/ BALBEKOV V.I., BULATOV E.A., DEMYANCHUK V. I, et al, IEEE Transactions on Magnetics, v. MAG-17, 5 (1981) 1886 .

/3/ ANDREYEV N.I., BAL̈BEKoV V.I., BULATOV E.A. et al. Preprint IHEP 82-31, Serpukhov, 1982 .

/4/ A Progress Report on the Energy Doubler, Saver, Collider Project, FNAL Design Report, 1976.

15/ BALBEKOV V.I., GERTSEV K.F., SMIRNOV N.L. et al. Preprint IHEP 82-134, Serpukhov, 1982.

/6/ Balbekov V.I., TKaChenko L.M. Preprint IHEP 82-167, Serpukhov, 1982. 